\title{
A natureza paratática das causais explicativas em português*
}

\author{
Madalena Colaço, Gabriela Matos \\ Faculdade de Letras da Universidade de Lisboa, Centro de Linguística da Universidade de \\ Lisboa
}

\begin{abstract}
:
Causal explicative clauses headed by the connectors pois, que and porque in Portuguese, despite presenting some properties of subordination establish a paratactic relation with the sentence they are related to. We argue that they are parenthetical clauses that exhibit the properties of specifying coordination.
\end{abstract}

Keywords: explicative clauses, subordination, parataxe, specifying coordination, Portuguese.

Palavras-chave: orações explicativas, subordinação, parataxe, coordenação especificante, português.

\section{Introdução}

Em português, as orações iniciadas por pois, que e porque, ilustradas em (1)-(3), têm sido caracterizadas como coordenadas (e.g. Lobo, 2001, 2003), como subordinadas (e.g. Bechara, 1999; Matos, 2003, 2004, 2006), como coordenadas e subordinadas, consoante a natureza do enunciado em que ocorrem (Said Ali, 1931; Cunha \& Cintra, 1984), ou ainda como unidades discursivas que não são configuráveis no âmbito da gramática da frase e constituem unidades textuais autónomas (Peres \& Mascarenhas, 2006; Lopes, 2012).

(1) Os alunos regressaram de férias, pois as praias estão quase desertas.

(2) A Maria deve estar doente, que ainda não apareceu nas aulas.

(3) A Maria está triste, porque está muito calada.

Na Teoria de Princípios e Parâmetros atual, a distinção sintática entre subordinação e coordenação não é captada em termos de construções, que são tidas como mecanismos pré-teóricos, nem em termos das representações estruturais, uma vez que estas podem ocorrer tanto na coordenação como na subordinação: a configuração especificador-núcleo-complemento, ocorre nas subordinadas completivas e nas coordenadas integradas; a de adjunção está presente nos tratamentos clássicos das subordinadas adverbiais (cf. Lobo, 2003 e bibliografia aí citada, Chomsky, 2004, 2013) e nas orações coordenadas parentéticas (cf. Matos, 2009; Colaço \& Matos, 2010; Matos \& Colaço, 2011) ou na coordenação "não estruturada" (Chomsky, 2013). Assim, neste quadro de referência, a distinção entre coordenação e subordinação deve fundamentalmente basear-se nos traços distintivos dos núcleos funcionais $\mathrm{C}$ ou Conj e nas propriedades específicas dos itens selecionados no Léxico para instanciar esses núcleos. Porém, alguns conectores parecem resistir a uma inclusão incontroversa na classe dos coordenadores ou dos subordinadores. É o caso de alguns conectores causais em diferentes línguas, nomeadamente no português.

Neste trabalho, defenderemos que estas orações, no português, apesar de exibirem propriedades morfossintáticas da subordinação no domínio frásico local que encabeçam, estabelecem com a frase a que estão associadas um nexo paratático e devem ser analisadas como uma instância de coordenação especificante, que faz apelo a um núcleo conector próprio, designado como Par(entético) (de Vries, 2009).

\section{Orações explicativas versus causais}

A distinção entre as orações explicativas e as orações causais não é pacífica e tem sido alvo de variadas reflexões. Com efeito, para além da discussão subordinação versus coordenação, outros aspetos interferem nesta distinção, tais como os diferentes valores que as mesmas unidades linguísticas - pois, que e porque - podem assumir em diferentes contextos.

Uma das ideias dominantes é que a oposição entre explicativas e causais se estabelece, em termos semânticos e pragmáticos: as causais expressam um nexo de causalidade relativamente à predicação contida num enunciado, que leva a que sejam frequentemente definidas como causais de re, enquanto as explicativas

\footnotetext{
* Este estudo foi desenvolvido no âmbito do projeto UID/LIN/00214/2013, financiado pela FCT. Agradecemos a todos os que nos fizeram comentários que permitiram melhorar o trabalho aqui apresentado, em especial aos participantes do $30^{\circ}$ Encontro Nacional da Associação Portuguesa de Linguística realizado em 2014.
} 
explicitam um nexo de justificação sobre uma enunciação, razão pela qual são, por vezes, designadas causais de dicto $^{1}$. De acordo com esta caracterização, enquanto, nas frases que apresentámos em (1)-(3), ocorrem orações explicativas, em (4)-(6) ocorrem orações causais:

(4) A Maria está aflita pois tem uma dor de dentes.

(5) Hoje está mais frio, que a temperatura baixou muito.

(6) A Maria atrasou-se porque o despertador não tocou.

As paráfrases que se seguem explicitam a diferença de interpretação associada a estes dois tipos de orações. As causais em (4)-(6) admitem paráfrases em que o conteúdo da oração causal é explicitamente apresentado como a causa da situação reportada pela oração a que está associada:

(7) A Maria está aflita. Isto acontece por causa de ela ter uma dor de dentes.

(8) Hoje está mais frio. Isto acontece por causa de a temperatura ter baixado muito.

(9) A Maria atrasou-se. Isto aconteceu por causa de o despertador não ter tocado.

Pelo contrário, as frases explicativas em (1)-(3) podem ser adequadamente parafraseadas como em (10)(12), em que se expressa o motivo da enunciação da frase relacionada:

(10) Os alunos regressaram de férias. Digo isto por as praias estarem quase desertas.

(11) A Maria deve estar doente. Digo isto porque ainda não apareceu nas aulas.

(12) A Maria está triste. Digo isto porque está muito calada.

Do mesmo modo, em explicativas como (1)-(3), o motivo da enunciação não é interpretado como uma causa da situação denotada pela oração relacionada, como mostra a inadequação das seguintes paráfrases:

(13) Os alunos regressaram de férias. \#Isto acontece por causa de as praias estarem quase desertas.

(14) A Maria deve estar doente. \#Isto acontece por causa de ainda não ter aparecido nas aulas.

(15) A Maria está triste. \#Isto acontece por causa de estar muito calada.

No entanto, a distinção entre o nexo de justificação e o nexo de causalidade nem sempre é óbvia, como se pode constatar, por exemplo, nos seguintes dados, que admitem ambas os tipos de paráfrases, como explicitado em (18), para o exemplo em (16):

(16) As ruas devem estar brancas, pois nevou toda a noite.

(17) Hoje deves ter tido frio, que a temperatura baixou muito.

(18) a. As ruas devem estar brancas. Isto deve ter acontecido porque nevou toda a noite.

b. As ruas devem estar brancas. Digo isto porque nevou toda a noite.

Conscientes das questões que permanecem em aberto, assumiremos, neste trabalho, que a distinção entre causais e explicativas é de natureza semântica e pragmática, e adoptaremos sem questionar a definição de oração (causal) explicativa acima apresentada.

\section{O comportamento sintático e discursivo das explicativas - uma visão comparativa}

O valor explicativo destas orações tem sido correlacionado com a sua menor integração estrutural e semântica nas frases relacionadas, tanto no português como noutras línguas. Assim, vários estudos têm distinguido causais e explicativas com base nesta diferença: as orações causais são consideradas como orações subordinadas adverbiais integradas no predicado da oração subordinante, na qual desempenham uma função sintática e semântica, como adjuntos causais, enquanto as orações explicativas são frequentemente tidas como

\footnotetext{
1 Diferentes tipos de relações causais têm sido distinguidos na literatura. Galán Rodriguez (1999) e M.H. Lopes (2004) mencionam as seguintes dicotomias, que parcialmente se recobrem: causa real ou externa vs. causa lógica (Gramáticas latinas), causa de re ou causa de enunciado vs. causa de dicto ou causa de enunciação (Bello 1847); causa propriamente dita, reportando-se à asserção do enunciado vs. causa explicativa, relativa à pressuposição do enunciado (Santos Rio, 1981); causa de conteúdo vs. causa epistémica (Noordmann \& Blijzer, 2000); causa semântica vs. causa pragmática (Sanders, Sporen \& Norman, 1992), causa efetiva vs. causa formal (Giusti, 1991).

Galán Rodriguez propõe uma caracterização mais granular de causa e distingue dois tipos maiores, cada um com dois subtipos: a causa propriamente dita, abarcando como subtipos a causa-feito e a motivação-resultado; e a causa explicativa, exibindo a explicativa propriamente dita, que expressa as circunstâncias pressupostas ou assumidas como habituais, e a explicativa hipotética, que relaciona a explicativa com a enunciação (Galán Rodriguez, 1999:3600-3602).
} 
orações que estabelecem uma relação de parataxe com a oração correlacionada. Essa relação de parataxe é identificada com a coordenação na tradição gramatical (cf. Said Ali, 1931, Cunha \& Cintra, 1984), e com a coordenação ou outras estratégias de parataxe, como, por exemplo, a suplementação (Huddleston et al., 2002), na literatura atual.

Assim, conectores como weil em alemão e porque em português, que podem ocorrer em orações explicativas e em orações adverbiais causais integradas, têm sido distinguidos, não só pelo sentido, mas também pelo comportamento sintático, revelador do seu nível de integração na oração relacionada. Com efeito, em alemão, a presença de weil causal determina comportamentos característicos da subordinação nesta língua, exigindo que o verbo flexionado ocorra em posição final de frase, como em (19); pelo contrário, quando pode assumir um sentido explicativo, weil, no alemão coloquial, é compatível com o verbo em posição V2 na frase, como em (20), usual nas frases independentes (cf. (21)), como referem Antomo (2012) e Catasso (2014):

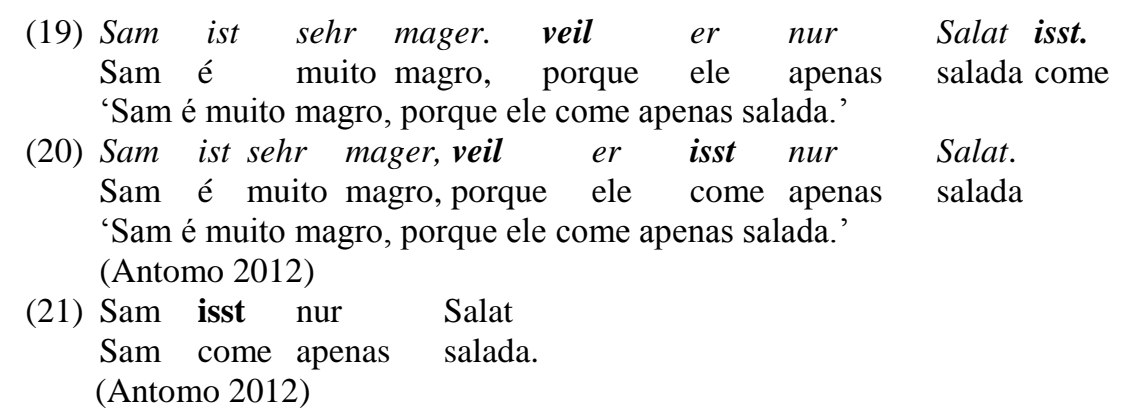

Antomo (2012) mostra igualmente que a oração weil-V final e a de weil-V2 apresentam propriedades distribucionais distintas, nomeadamente no que diz respeito à sua mobilidade: apenas a oração de weil-V final pode ocorrer em posição inicial:

(22) a. Weil Paula krank ist, war sie heute nicht in der Schule.
porque Paula doente está, foi ela hoje não à escola
'Porque a Paula está doente, não foi hoje à escola.'
b. *Weil Paula ist krank, war sie heute nicht in der Schule.
porque Paula está doente, foi ela hoje não à escola

No entanto, Antomo destaca que em alemão, as orações de weil-V2 não apresentam unicamente uma interpretação explicativa. As orações de weil-V2, podem expressar uma evidência para proposição da oração prévia proferida pelo locutor, ou para o seu ato de fala, mas podem igualmente exibir uma interpretação idêntica à das orações de weil-V final, ou seja, uma razão para o conteúdo proposicional da oração principal (cf. Antomo, 2012: secções 3.2, 3.3. e 3.4). Estes dados sugerem que há uma distinção entre o comportamento sintático das orações causais e a sua classificação como explicativas ou causais propriamente ditas, e corroboram a posição que adotamos na secção anterior, ao assumirmos que a distinção entre explicativas e causais é fundamentalmente do foro da semântica e da pragmática.

Trabalhos desenvolvidos na última década do século XX mostraram igualmente que nem todas as orações subordinadas adverbiais são geradas como integradas e que, pelo contrário, algumas ocupam basicamente posições periféricas da frase (e.g, para o italiano Giusti, 1991; Lonzi, 1991; para o espanhol Fernandez Lagunilla, 1999, Galán Rodrigez, 1999; para o português Lobo, 2002, 2003). Deste modo, no âmbito das orações explicativas, Lobo (2003) considera a existência de orações subordinadas adverbiais periféricas explicativas (e.g., as iniciadas por conectores como uma vez que, já que, como), a par de explicativas coordenadas, iniciadas com pois, que e porque).

Assim, recoloca-se a questão da classificação das orações explicativas, em si mesmas, como um fenómeno de parataxe ou de hipotaxe, tendo em vista o seu comportamento sintático, discursivo e prosódico.

Quirk et al. (1985) discutem a hipótese de incluir for nos conectores subordinativos ou nos coordenativos. Com base no seu comportamento sintático, concluem que for, em inglês, é um subordinador. Embora as frases finitas iniciadas com for partilhem com as estruturas de coordenação algumas propriedades - nomeadamente, o facto de a oração iniciada por for não poder ser anteposta (23a) vs. (23b) e aceitar dificilmente ser coordenada (24) -, apresenta propriedades características da subordinação: for, tal como os complementadores conjuncionais em inglês, não admite a omissão do sujeito na frase finita que introduz (cf. (25)); for não pode conectar unidades menores do que a frase (cf. (26); for não pode articular frases subordinadas (27), (cf. Quirk, 1985: 922-924): 
(23) a. He asked to be transferred, for he was unhappy.

b. *For he was unhappy, he asked to be transferred.

(24) ??He asked to be transferred, for he was unhappy and for he saw no possibility of promotion.

(25) *He did not want it for was obstinate.

(26) *The baby was crying for hungry.

(27) *He said that he wanted to be transferred since he was unhappy for because he saw no possibility of promotion.

Do mesmo modo, no que diz respeito ao português europeu, Matos (2003, 2004, 2006) e Matos \& Raposo (2013) assumem que as partículas explicativas pois, que e porque apresentam predominantemente um estatuto de complementadores conjuncionais, apesar de manifestarem alguns comportamentos tipicamente atribuídos às conjunções coordenativas ${ }^{2}$. Com efeito, tal como as frases coordenadas, as explicativas de pois e que não podem ser antepostas à frase com que estão correlacionadas, como mostram os exemplos em (28):

(28) a. A Maria saiu de casa à pressa, pois/que/porque as luzes ficaram acesas.

b. *Pois/que as luzes ficaram acesas, a Maria saiu de casa à pressa.

c. \#Porque as luzes ficaram acesas, a Maria saiu de casa à pressa.

Porém, estes conectores comportam-se como complementadores face a várias outras propriedades:

Como os complementadores conjuncionais, só ocorrem em frases finitas ${ }^{3}$, (29), diferentemente das conjunções coordenativas, que são neutras relativamente à natureza finita ou infinitiva das frases que conectam (30):

(29) A Ana acha que o Pedro foi para as aulas, pois/porque/que não $\{$ estava/*estar $\}$ em casa quando ela chegou.

(30) a. O réu afirmou que ficara em casa e que estivera acompanhado pelos amigos.

b. O réu afirmou não ter estado no local do crime nem ter nenhum cúmplice.

Por oposição às conjunções coordenativas (32), os conectores explicativos não articulam constituintes não frásicos (31):

(31) *A Paula está esfomeada pois/porque/que irascível.

(32) A Paula está esfomeada e irascível.

Os conectores explicativos em análise não conectam frases subordinadas, (33), diferentemente da maioria das conjunções coordenativas, (34):

(33) *A Paula saiu, já que tinha fome pois/porque/que visto que estava cansada.

(34) A Paula saiu, já que tinha fome e visto que estava cansada.

Finalmente, não aceitam elipse do verbo flexionado (gapping), (35), diferentemente das conjunções de coordenação, (36):

(35) *A Paula comprou uma revista pois/porque/que a Ana um jornal.

(36) A Paula comprou uma revista e/mas a Ana um jornal.

Em suma, as orações explicativas nas diferentes línguas podem exibir propriedades que as distinguem das causais propriamente ditas. No entanto, o valor explicativo não está necessariamente associado a um estatuto de coordenação. Em português europeu, há orações causais explicativas que são consensualmente assumidas como subordinadas e um subgrupo de explicativas, iniciadas por pois, que e porque, que têm suscitado dúvidas quanto à sua inclusão na coordenação ou na subordinação. No entanto, o comportamento sintático que estas explicativas exibem leva-nos a classificar os conectores que as introduzem como complementadores e, consequentemente, as orações que encabeçam como subordinadas.

\footnotetext{
${ }^{2}$ Pois, que e porque apresentam propriedades diversas, e não ocorrem exatamente nos mesmos contextos (cf. M. H. Lopes, 2004)

${ }^{3}$ Recorde-se que os complementadores proposicionais ou sem realização lexical ocorrem nas orações subordinadas não-finitas.
} 


\section{As explicativas como orações não integradas}

$\mathrm{Na}$ literatura de várias línguas tem sido frequentemente referido que as orações explicativas apresentam uma fraca coesão relativamente à frase com que estão associadas (vejam-se, por exemplo, para o português Said Ali, 1931; Cunha \& Cintra, 1984; Peres, 1997; Matos, 2004, 2006; para o espanhol Gálan Rodriguez, 1999; para o alemão Antomo, 2012; Catasso, 2014).

Com efeito, conforme notado para o português por Peres $(1997)^{4}$, as explicativas não podem ser alvo de focalização, de que decorre a impossibilidade de ficarem sob o escopo da negação da frase à qual estão associadas, ou de constituírem uma resposta adequada a uma pergunta de instanciação:

(37) a. *A Maria não saiu de casa à pressa, pois/que/porque as luzes ficaram acesas, mas sim por outro motivo. $^{5}$

b. Porque é que a Maria saiu de casa à pressa? \#Porque as luzes ficaram acesas.

A autonomia discursiva das explicativas face à frase relacionada levou alguns autores a afirmarem que estas unidades linguísticas não podem ser caracterizadas em termos frásicos, mas apenas discursivos: da articulação destas orações, não se obteria uma frase complexa, mas um texto com dois fragmentos textuais autónomos, ainda que correlacionados (Peres \& Mascarenhas, 2006; Lopes, 2012).

Hudlleston et al. (2002) captam este tipo de relação através do conceito de Suplementação, que é também adotado em Matos \& Raposo (2013). A Suplementação é um processo em que o suplemento (por outros autores designado como constituinte parentético) é, em Sintaxe, independente da frase hospedeira e com ela mantém apenas um vínculo nocional ${ }^{6}$.

Contudo, a hipótese da Suplementação levanta dois problemas fundamentais. Em primeiro lugar, o facto de a explicativa requerer obrigatoriamente a presença da frase correlacionada (veja-se (38)) mostra que de algum modo lhe está estruturalmente associada:

(38) \#Pois/que/porque as luzes ficaram acesas.

Em segundo lugar, assumindo a Teoria de Princípios e Parâmetros atual, a Suplementação não capta a relação entre a estrutura construída e a linearização dos constituintes, nem permite derivar a unidade formada pela explicativa e a frase correlacionada. Com efeito, mantendo, como na Teoria de Princípio de Parâmetros, que não há relação directa entre a componente fonológica e a componente semântica, se a explicativa for tardiamente inserida na hospedeira por Late Merge (cf. Chomsky, 2004) na componente fonológica/Forma Fonética, a explicativa não é interpretada em Semântica/Forma Lógica, e se for inserida na hospedeira em Forma Lógica, não é audível em Forma Fonética.

Por estes motivos, não consideramos que a Suplementação dê conta da relação entre a oração explicativa e a sua hospedeira. Alternativamente, adotaremos a hipótese de coordenação especificante, sugerida por de Vries (2006, 2007, 2009) para diversas construções paratáticas.

\section{As orações explicativas como um tipo de parentéticas}

As orações explicativas integram-se num tipo mais geral de construções paratáticas, as parentéticas, o que justifica a sua menor coesão estrutural com a frase hospedeira. Com efeito, do facto de ser parentética, decorre a possibilidade de a explicativa (como outras parentéticas) poder ocorrer não só após a frase a que está associada, como em (39a), mas noutras posições da frase hospedeira, associada a outros constituintes, como em (39b), facto que não tem sido destacado na literatura:

(39) a. Os alunos regressaram às aulas, pois/porque/que as praias estão desertas.

\footnotetext{
${ }^{4} \mathrm{O}$ mesmo comportamento é exibido pelas orações de weil-V2 em alemão, como mostra Antomo (2012).

${ }^{5}$ No entanto, veja-se que existem contextos que permitem uma interpretação em que a oração está sob o escopo da negação que ocorre na hospedeira:

(i) Eu não acho que está gente em casa porque as luzes estão acesas (mas sim porque o carro está na garagem).

Por um lado, é certo que, neste caso, a oração iniciada por porque parece ser integrada (o que se reflete na prosódia e na ausência de vírgula na grafia). Mas, por outro lado, não é evidente que tenha um valor causal e não explicativo, de justificação de uma enunciação (neste caso, mais especificamente, de justificação do raciocínio que levou o falante a uma determinada enunciação, já que uma frase como a de cima apenas se torna adequada quando produzida num contexto de integração). Não cabendo no âmbito deste trabalho, dados como este mostram a necessidade de um maior aprofundamento da distinção entre explicativas e causais e da correspondência com a distinção entre não integradas e integradas em português.

${ }^{6}$ Esta mesma posição é assumida por autores que não adotam a designação de Suplementação para dar conta dos parentéticos e é frequentemente conhecida como a hipótese da orfandade radical dos constituintes parentéticos (e.g. Hageman, 1991/2009).
} 
b. O João, porque/pois/que eu conheço-o bem, vai ganhar essa bolsa de estudos.

O estatuto parentético de uma expressão é, normalmente, reconhecido através de uma combinação de aspetos de diferente natureza (veja-se Frota, 2000; Déhé \& Kavalova, 2007; Schneider, 2007, entre outros). A presença de tais propriedades nas orações explicativas leva-nos a integrá-las na família das construções parentéticas.

Assim, do ponto de vista prosódico, as parentéticas são prosodicamente independentes da frase hospedeira: quando ocorrem na periferia direita, não afetam a entoação da hospedeira; quando são intercaladas, provocam uma rutura prosódica na hospedeira, representada, na grafia, por vírgulas, por parênteses ou por travessões. Este comportamento é igualmente atestado nas orações explicativas:

(40) Os alunos regressaram às aulas, pois/porque/que as praias estão desertas.

(41) a. O João, porque/pois/que eu conheço-o bem, vai ganhar essa bolsa de estudos

b. O João (porque/pois/que eu conheço-o bem) vai ganhar essa bolsa de estudos.

c. O João - porque/pois/que eu conheço-o bem - vai ganhar essa bolsa de estudos.

Sintaticamente, a relação estrutural que liga a parentética à hospedeira torna possível, em muitos casos, a sua ocorrência em diferentes posições. Embora com restrições, que referiremos com mais pormenor mais adiante, essa possibilidade verifica-se também nas orações explicativas (cf. (41) e (42)):

(42) a. O João vai ganhar essa bolsa de estudos, porque/pois/que eu conheço-o bem.

b. O João vai ganhar, porque/pois/que eu conheço-o bem, essa bolsa de estudos.

c. O João vai, porque/pois/que eu conheço-o bem, ganhar essa bolsa de estudos.

Em termos de significado, as expressões parentéticas correspondem a proposições autónomas, embora, frequentemente, estabeleçam uma ligação com a hospedeira (ou, eventualmente, com um constituinte da hospedeira). Esta mesma propriedade se verifica nas explicativas ${ }^{7}$. Não tendo um valor restritivo, o significado da explicativa não afeta o significado da hospedeira (ou de um constituinte da hospedeira). Assim, as frases complexas envolvendo a explicativa podem ser parafraseadas por frases independentes justapostas, como ilustrado em (43) para as frases em (39):

(43) a. Os alunos regressaram às aulas. As praias estão desertas.

b. O João vai ganhar essa bolsa de estudos. Eu conheço-o bem.

Do ponto de vista informacional, a expressão parentética adiciona uma informação extra, pelo que corresponde sempre a informação secundária. As orações explicativas - o que está, de resto, refletido na sua própria designação - fornecem uma explicação ou justificação acerca da enunciação da proposição que corresponde à frase hospedeira, ou, eventualmente, acerca de uma expressão nela contida. Neste sentido, podemos afirmar que as explicativas fornecem mensagens secundárias.

Por se verificar este conjunto de propriedades, assumiremos, então, que as orações explicativas são um tipo de parentéticas.

\section{As parentéticas como um caso de coordenação especificante}

Em de Vries (2007, 2009), é proposto um tratamento uniforme das estruturas paratáticas - incluindo estruturas de coordenação padrão, estruturas apositivas e estruturas parentéticas - como instâncias de coordenação. Esta ideia resulta da consideração da existência de um quarto tipo de coordenação (para além da coordenação copulativa, disjuntiva e adversativa), que o autor designa por coordenação especificante, na linha de Koster $2000^{8}$, e que engloba as estruturas apositivas e as parentéticas.

Para de Vries, as estruturas paratáticas são formadas por uma operação sintática distinta daquela que está presente na subordinação (ou hipotaxe). Distingue, assim, dois tipos de inclusão estrutural, a $d$-inclusion e a $b$-inclusion, resultantes de dois tipos de Merge, $d$-Merge e $b$-Merge, respetivamente.

\footnotetext{
${ }^{7}$ Esta ideia está presente em Lopes (2012), que afirma que, nas construções com orações explicativas - ou, usando o termo da autora, orações causais de enunciação -, é possível distinguir dois atos ilocutórios, contrariamente ao que se verifica no caso das construções com orações causais de enunciado, em que existe um único ato ilocutório.

${ }^{8}$ Koster (2000) considera as construções equativas (ex: John built something beautiful: a golden igloo) como um caso de coordenação especificante, sugerindo a existência de uma categoria Colon Phrase resultante da projeção de um núcleo coordenativo especificante foneticamente nulo (representado por ": "), associado ao significado de "nomeadamente".
} 
O alargamento de b-Merge a todos os casos de coordenação suscita vários problemas que nos levam a não aceitar integralmente esta proposta ${ }^{9}$; porém, uma análise detalhada desta questão está fora do alcance do presente artigo. No entanto, no que diz respeito às orações parentéticas explicativas, o conceito de coordenação especificante parece especialmente adequado.

Nesta perspetiva, quando $b$-Merge é desencadeado por um núcleo coordenativo especificante, conduz à formação de uma estrutura de coordenação que se caracteriza pelas seguintes propriedades centrais (cf., por exemplo, de Vries, 2006: 239):

(44) (i) Os termos coordenados estão normalmente ligados por um conector coordenativo foneticamente nulo (embora, em certos casos, possa ocorrer um conector lexicalizado, entendido como o spellout do núcleo coordenativo);

(ii) o conector coordenativo especificante bloqueia c-comando;

(iii) na escrita, os termos coordenados são separados por vírgula (em correlação com aspetos fonológicos);

(iv) o segundo termo coordenado é produzido com uma entoação baixa;

(v) o segundo termo coordenado é um constituinte não restritivo;

(vi) a estrutura é assimétrica, no sentido em que é sempre o segundo termo que especifica o primeiro.

A consideração deste tipo de coordenação assenta também em aspetos semânticos e informacionais: considera-se que B especifica A se B adiciona informação a A. Assim, a especificação corresponde a informação extra, eventualmente a uma explicação, envolvendo, por isso, necessariamente, a presença de uma informação secundária.

As diferenças que se verificam entre as estruturas de coordenação especificante - nomeadamente, as aposições e as parentéticas - são atribuídas às propriedades de dois núcleos conjuncionais especificantes distintos: o núcleo bivalente $\&:^{10}$, que participa nas estruturas apositivas, e o núcleo monovalente Par, que integra as estruturas parentéticas. Assim, a estrutura interna de uma parentética é a seguinte ${ }^{11}$ :

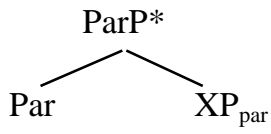

A ligação da parentética à frase hospedeira é feita por adjunção, de que resulta uma estrutura como a representada em (46), para as parentéticas interpoladas. Nesta estrutura, dados os efeitos produzidos pela presença de um núcleo conjuncional especificante, $\mathrm{Y}$ não c-comanda $\mathrm{XP}_{\mathrm{par}}$, nem nenhuma categoria contida na frase hospedeira c-comanda a parentética.

(46)

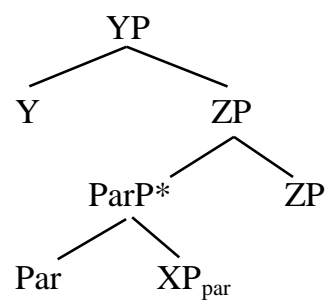

As construções com orações explicativas partilham diversas propriedades que caracterizam, em termos gerais, a coordenação especificante:

Em primeiro lugar, as orações explicativas têm um valor que pode ser considerado especificante, no sentido em que fornece uma justificação do locutor para a enunciação da predicação que ocorre na hospedeira, como ilustram as paráfrases em (47b)-(48b):

\footnotetext{
${ }^{9}$ Em de Vries (2007e 2009) é sugerida a ideia de que a operação b-Merge é desencadeada por qualquer núcleo conjuncional coordenativo. Esta ideia levanta, no entanto, problemas empíricos, nomeadamente pelo facto de pressupor a inexistência de relações de c-comando entre os termos coordenados. Variados estudos têm mostrado a existência de c-comando do primeiro termo coordenado sobre o segundo. Assim, assumimos que, tal como para a subordinação, também na coordenação há frases coordenadas integradas, em que o c-comando do primeiro termo sobre o segundo se verifica, e coordenadas não-integradas, que incluem as parentéticas, em que o c-comando a partir da expressão correlacionada é cancelado (cf. Matos, 2009)

${ }^{10}$ Não nos debruçaremos sobre o núcleo bivalente \&:, dado que o estudo das orações apositivas está fora do alcance do presente trabalho.

${ }^{11}$ de Vries usa o asterisco, nas representações, para explicitar o facto de a estrutura ter sido formada por $b$-Merge.
} 
(47) a. A Maria deve estar doente, que/pois/porque ainda não apareceu nas aulas.

b. A Maria deve estar doente: ainda não apareceu nas aulas.

(48) a. A Maria saiu de casa à pressa, pois/porque deixou as luzes acesas.

b. A Maria saiu de casa à pressa: deixou as luzes acesas.

Adicionalmente, as orações explicativas, como as coordenadas em geral, podem ser reiteradas (49a) e recursivas $(49 b)$ :

(49) a. A Maria esteve a pintar, que tem as mãos sujas, que até no cabelo tem tinta.

b. A Maria esteve a pintar, que tem as mãos sujas, que as manchas de tinta custam a sair.

Além disso, na coordenação especificante, a conjunção abstrata (neste caso, Par) bloqueia o c-comando a partir da oração hospedeira. Tal justifica o cancelamento de efeitos do Princípio C, (cf. em (50) a relação de coreferência entre o pronome ela e a expressão referencial a Maria), e a ausência de escopo da negação da oração hospedeira sobre a explicativa (cf. (51)):

(50) Ela $\mathrm{a}_{\mathrm{i}}$ deve estar doente, que/pois/porque a Maria $\mathrm{i}_{\mathrm{i}}$ nunca falta às aulas.

(51) Ela não saiu, que/pois/porque as luzes estão acesas.

Por outro lado, as orações explicativas exibem propriedades que as afastam dos casos de coordenação simétrica tradicionalmente considerados, em particular a impossibilidade de aceitarem movimento de constituintes a partir da explicativa, mesmo em contextos próximos dos de movimento simultâneo, ou seja, com um constituinte lexical associado a duas posições vazias, como em $(52 \mathrm{c})^{12}$ :

(52) a. O Pedro perdeu o telemóvel, que/pois/porque eu vi o telemóvel em cima de uma cadeira.

b. *O que ${ }_{i}$ é que o Pedro perdeu o telemóvel, que/pois/porque eu vi [- $]_{i}$ em cima de uma cadeira?

c. ??O que ${ }_{i}$ é que o Pedro perdeu $[-]_{i}$, que/pois/porque eu vi $[-]_{i}$ em cima de uma cadeira?

$\mathrm{Na}$ verdade, esta é uma propriedade que as explicativas partilham com as restantes parentéticas, incluindo as parentéticas coordenadas, como ilustrado em (53):

(53) a. A Maria perdeu o telemóvel, e ela adorava o telemóvel, quando foi a casa do Pedro.

b. *O que é que a Maria perdeu o telemóvel, e ela adorava [- $]_{i}$, quando foi a casa do Pedro?

c. ??O que é que a Maria perdeu $[-]_{\mathrm{i}}$, e ela adorava $[-]_{\mathrm{i}}$, quando foi a casa do Pedro?

Assim, concluímos que a hipótese de tratamento das orações explicativas, tendo em conta o seu estatuto parentético e o nexo paratático que estabelecem com a frase hospedeira, como instâncias de coordenação especificante poderá ser uma forma de captar o comportamento característico deste tipo de orações, que se evidencia pelo facto de, como já foi referido, conciliarem propriedades normalmente atribuídas à coordenação com outras que tipicamente se associam à subordinação.

\section{Posições das explicativas relativamente à hospedeira}

De acordo com Lopes (2012), as orações explicativas (ou causais de enunciação ou causais de dicto) estabelecem um nexo causal não com uma predicação (como acontece no caso das causais de enunciado ou causais de re), mas com a enunciação dessa predicação. Por este motivo, como já mencionámos atrás, podem ser parafraseadas por expressões iniciadas por: "Digo isto porque..." (e não por expressões iniciadas por "Isto aconteceu porque/por causa de...”). De acordo com a autora (cf. também Lopes, 2009), entre as predicações relacionadas estabelece-se um nexo de justificação. A presença desta relação de justificação está na base de algumas propriedades das orações explicativas descritas na literatura, entre as quais, segundo Lopes (2012), da impossibilidade de inverter a ordem dos termos, ilustrada em (54):

(54) a. Os alunos regressaram de férias, pois/que/porque as praias estão desertas.

b. *Pois/que/porque as praias estão desertas, os alunos regressaram de férias.

\footnotetext{
${ }^{12}$ Com efeitos dos casos de movimento simultâneo, admite-se classicamente que os constituintes movidos deixam uma cópia que é ccomandada pela forma realizada desses constituintes deslocados.
} 
Se, na linha daquilo que propusemos atrás, pensarmos nas orações explicativas como expressões parentéticas, podemos observar o contraste que se verifica entre (54a) e (54b) não propriamente como o resultado de uma inversão entre os termos envolvidos na construção, mas como a evidência de que existem limitações respeitantes às posições que as parentéticas podem ocupar em relação à hospedeira. Veja-se, por exemplo, Matos \& Colaço (2010), em que a impossibilidade de ocorrência das parentéticas na periferia esquerda da hospedeira foi atribuída ao nexo que se estabelece entre os dois termos envolvidos na construção (comentário, juízo, etc.).

Assumindo que a predicação contida na oração explicativa introduz uma justificação sobre a enunciação da predicação com a qual está relacionada, veja-se, no entanto, a possibilidade de estabelecermos algumas distinções, que poderão estar subjacentes a contrastes sintáticos respeitantes às posições que podem ser ocupadas pelas explicativas. Confrontem-se os seguintes dados:

(55) O Pedro alugou a casa de Lisboa aos amigos de Paris, que/pois/porque só se fala disso no bairro.

(56) O Pedro alugou a casa de Lisboa aos amigos de Paris, que/pois/porque acho que não teria coragem de vender.

(57) O Pedro alugou a casa de Lisboa aos amigos de Paris, que/pois/porque tenho visto as janelas abertas.

(58) O Pedro alugou a casa de Lisboa aos amigos de Paris, que/pois/porque tenho visto os rapazes no café.

Nas frases de cima, embora ocorra, em todas elas, uma oração explicativa na periferia direita que introduz uma explicação acerca da enunciação de outra predicação, essa justificação pode incidir sobre a predicação no seu todo, ou apenas sobre um elemento seu constituinte, como mostram as seguintes paráfrases:

(59) O Pedro alugou a casa de Lisboa aos amigos de Paris. Digo isto (que o Pedro alugou a casa de Lisboa aos amigos de Paris) porque só se fala disso no bairro.

(60) O Pedro alugou a casa de Lisboa aos amigos de Paris. Digo que alugou porque acho que ele não teria coragem de vender.

(61) O Pedro alugou a casa de Lisboa aos amigos de Paris. Digo que alugou a casa de Lisboa porque tenho visto as janelas abertas.

(62) O Pedro alugou a casa de Lisboa aos amigos de Paris. Digo que alugou aos amigos de Paris porque tenho visto os rapazes no café.

A diferença notada acima tem consequências ao nível das posições ocupadas pela explicativa relativamente à hospedeira. Os dados mostram que a oração explicativa, podendo sempre ocorrer na periferia direita da hospedeira, poderá também, nos casos em que o nexo de justificação se estabelece relativamente a um dos elementos constituintes da hospedeira, ocupar outras posições, respeitando a seguinte restrição: a expressão relativamente à qual incide a justificação deve preceder a oração explicativa.

Assim, quando a oração explicativa fornece uma explicação sobre toda a predicação correspondente à hospedeira, apenas pode ocorrer na periferia direita:

(63) a. O Pedro alugou a casa de Lisboa aos amigos de Paris, que/pois/porque só se fala disso no bairro.

b. ??O Pedro alugou a casa, que/pois/porque só se fala disso no bairro, aos amigos de Paris.

c. ??O Pedro alugou aos amigos de Paris, que/pois/porque só se fala disso no bairro, a casa de Lisboa.

No entanto, quando a oração explicativa justifica, por exemplo, a enunciação da situação descrita pelo predicador, mais facilmente a oração explicativa poderá ocorrer em posições internas à hospedeira:

(64) a. O Pedro alugou a casa de Lisboa aos amigos de Paris, que/pois/porque acho que não teria coragem de vender.

b. O Pedro alugou, que/pois/porque acho que não teria coragem de vender, a casa de Lisboa aos amigos de Paris.

c. O Pedro alugou a casa de Lisboa, que/pois/porque acho que não teria coragem de vender, aos amigos de Paris. 
Os dados seguintes parecem confirmar que, quando o nexo de justificação se estabelece relativamente a um dos elementos constituintes da hospedeira (em (65) "a casa de Lisboa" e em (66) "aos amigos de Paris"), a oração explicativa, para além de poder ocorrer na periferia direita, pode também, embora com algumas reservas, ocorrer internamente à hospedeira, desde que precedida desse constituinte:

(65) a. O Pedro alugou a casa de Lisboa aos amigos de Paris, pois/porque tenho visto as janelas abertas.

b. ??O Pedro alugou, pois/porque tenho visto as janelas abertas, a casa de Lisboa aos amigos de Paris.

c. (?) O Pedro alugou a casa de Lisboa, pois/porque tenho visto as janelas abertas, aos seus amigos de Paris.

d. ??O Pedro alugou aos seus amigos de Paris, pois/porque tenho visto as janelas abertas, a casa de Lisboa.

(66) a. O Pedro alugou a casa de Lisboa aos amigos de Paris, pois/porque tenho visto os rapazes no café.

b. ??O Pedro alugou, pois/porque tenho visto os rapazes no café, a casa de Lisboa aos amigos de Paris.

c. ??O Pedro alugou a casa de Lisboa, pois/porque tenho visto os rapazes no café, aos amigos de $\underline{\text { Paris. }}$.

d. (?)O Pedro alugou aos amigos de Paris, pois/porque tenho visto os rapazes no café, a casa de Lisboa.

Os exemplos que apresentámos em (41) e (42b), e que aqui retomamos, mostram igualmente a possibilidade de a oração explicativa ocorrer imediatamente a seguir ao sujeito nos casos em que o nexo de justificação se relaciona especialmente com este constituinte da hospedeira:

(67) a. O João, porque/pois/que eu conheço-o bem, vai ganhar essa bolsa de estudos.

b. O João vai ganhar essa bolsa de estudos, porque/pois/que eu conheço-o bem.

Assim, tendo em conta o que dissemos nas secções anteriores e adoptando a noção de coordenação especificante parentética de Vries (2009), propomos, para as explicativas de pois, que e porque, as representações as estruturais em (68) e (69), respetivamente para a explicativas em posição final e para as interpoladas. Nos esquemas, materializamos o valor parentético pela notação ",":

(68) As aulas já começaram, que/pois/porque as praias estão desertas.

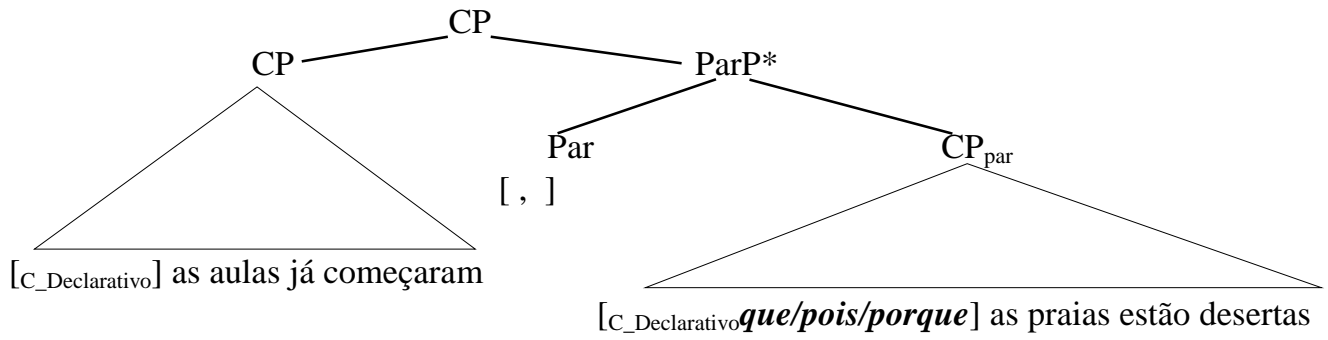

(69) O Pedro alugou, que/pois/porque acho que não teria coragem de vender, a casa de Lisboa aos amigos de Paris.

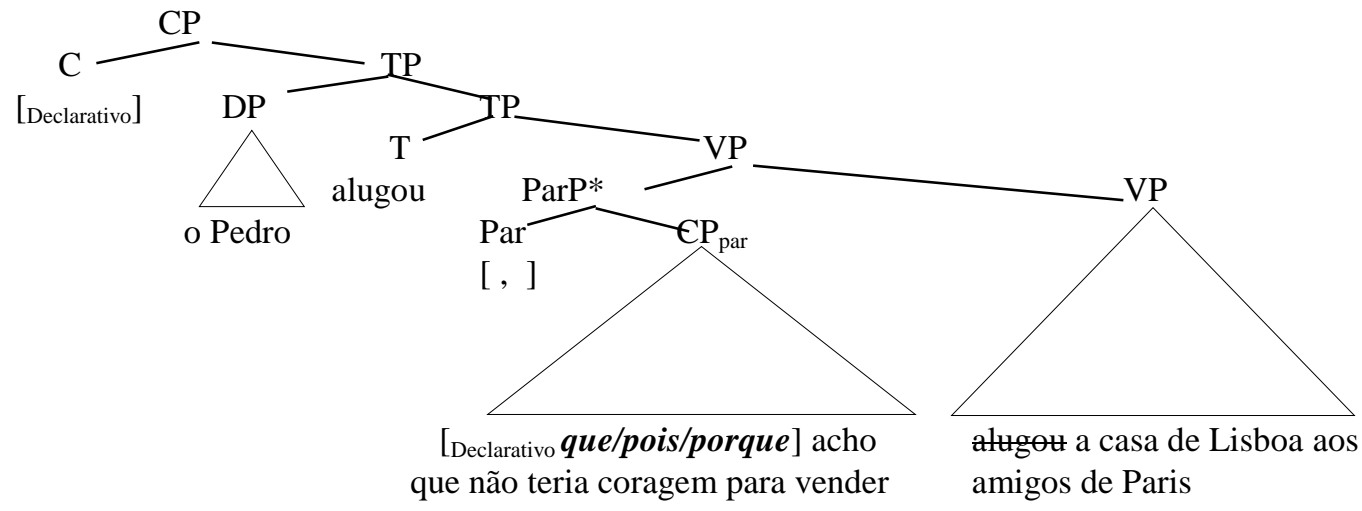




\section{Conclusões}

O alargamento da noção de coordenação a outros casos de parataxe com a noção de coordenação especificante revela-se particularmente eficaz para dar conta das orações explicativas em português.

A análise apresentada permite conciliar as evidências de que as orações explicativas de pois, que e porque apresentam um estatuto duplo: No domínio local que encabeçam, estes conectores funcionam como complementadores conjuncionais que determinam a finitude da proposição sobre a qual têm escopo. No seio frase em que estão hospedadas, as orações explicativas comportam-se como parentéticas, o que determina o seu comportamento não integrado.

Finalmente, a noção de coordenação especificante permite dar conta sintaticamente das construções que incluem parentéticas, e estabelecer uma correlação entre a sua posição na frase hospedeira e os constituintes sobre os quais incide a justificação explicativa.

\section{Referências:}

Antomo, Mailin. 2012. Interpreting embedded verb second. Proceedings of ConSOLE, 2012, 27-51, http://www.sole.leidenuniv.nl.

Bechara, Evanildo. 1999. Moderna Gramática Portuguesa. Rio de Janeiro: Lucerna.

Bello, Andrès .1847. Gramática de la lengua castellana. Tenerife: Aula de Cultura, 1981.

Colaço, Madalena \& Gabriela Matos. 2010. Estruturas coordenadas sem especificador realizado em português europeu". Diacrítica 24(1): 267-288 - Revista do Centro de Estudos Humanísticos, Série Ciências da Linguagem. V.N. de Famalicão: Centro de Estudos Humanísticos da Universidade do Minho \& Edições Húmus.

Catasso, Nicholas. 2014. The Case of V2 Causal Clauses in Spoken German: coordination, Subordination or Something In-Between? Comunicação apresentada ao colóquio Coordination/Subordination in Lisbon. Universidade de Lisboa.

Chomsky, Noam. 2004. Beyond Explanatory Adequacy. In Belletti, Adriana (ed.) Structures and Beyond - The Cartography of Syntactic Structures, vol. 3. Oxford: Oxford University Press, vol. 3, 105-131.

Chomsky, Noam. 2013. Problems of Projections. Lingua 130, 33-49.

Cunha, Celso \& Luís Filipe Cintra. 1984. Nova Gramática do Português Contemporâneo. Lisboa: Edições João Sá da Costa.

Galán Rodriguez, Carmen. 1999. La subordinación causal y final. In Bosque, Ignacio \& Violeta Demonte (dir.), Gramática Descriptiva de la Lengua Española, vol 3. Madrid: Espasa, 3597-3642.

Giusti, Giuliana . 1991. Frasi avverbiali: Temporali, causali e consecutive. In Renzi, Lorenzo, Giampolo Salvi \& Anna Cardinalletti (orgs). Grande Grammatica di Consultazionei, vol 2. Bologna: Il Mulino.

Déhé, Nicole \& Yordana Kavalova. 2007. Parentheticals: An Introduction. In Déhé, Nicole \& Yordana Kavalova (eds.). Parentheticals. Amsterdam/Philadelphia: John Benjamins.

Fernandez Lagunilla, Marina. 1999. Las construcciones de gerundio. In Bosque, Ignacio \& Violeta Demonte (dir.), Gramática Descriptiva de la Lengua Española, vol.2. Madrid: Espasa, 3443-3503.

Frota, Sónia. 2000. Prosody and Focus in European Portuguese. Phonological Phrasing and Intonation. New York NY: Garland.

Haegeman, Liliane. 1991/2009. Parenthetical adverbs: The radical orphanage approach. Dislocated elements in discourse: Syntactic, semantic, and discourse perspectives, ed. by B. Shaer, P. Cook, W. Frey \& C. Maienborn. London: Routledge, 331-47.

Huddleston, Rodney, Jonh Payne \& Peter Peterson. 2002. Coordination and Supplementation. In Huddlestone, Rodney \& Geoffrey Pullum (eds.). The Cambridge Grammar of the English Language, cap. 15. Cambridge: Cambridge University Press.

Koster, Jan. 2000. Extraposition as Parallel Construal. Ms.

Lobo Maria, 2001. Para uma sintaxe das orações causais do português, in C. Correia \& A. Gonçalves (eds.), Actas do XVI Encontro Nacional da Associação Portuguesa de Linguística, Lisboa, APL, pp. 290-306.

Lobo, Maria. 2002. On the structural position of non-peripheral adjunct clauses. Journal of Portuguese Linguistics, 1(1): 83-118.

Lobo, Maria. 2003. Aspectos da sintaxe das orações subordinadas adverbiais do português. Dissertação de Doutoramento. Universidade Nova de Lisboa, Lisboa.

Lonzi, Lidia. 1991. Frasi subordinati al gerundio. In Renzi, Lorenzo, Giampolo Salvi \& Anna Cardinalletti (orgs). Grande Grammatica di Consultazione. Bologna: Il Mulino, 571-592

Lopes, Ana Cristina Macário. 2009. Justification: a Coherence Relation. Pragmatics 19(2): 241-252.

Lopes, Ana Cristina Macário. 2012. Contributos para uma análise Semântico-pragmática das causais de enunciação no português europeu contemporâneo. Alfa, São Paulo, 56 (2): 451-468. 
Lopes, Maria Helena. 2004. Aspectos Sintáticos, Semânticos e Pragmáticos das Construções Causais Contributo para uma Reflexão sobre o Ensino da Gramática. Dissertação de Doutoramento, Porto, Universidade do Porto, Faculdade de Letras.

Matos, Gabriela. 2003. Estruturas de Coordenação. In Mateus M. H., A. Brito, I. Duarte, I. Faria, S. Frota, G. Matos, F. Oliveira, A. Villalva \& M. Vigário (orgs.). Gramática da Língua Portuguesa. Lisboa: Caminho, pp.229-259.

Matos, Gabriela. 2004. Coordenação Frásica vs. Subordinação Adverbial. In Freitas, Tiago \& Amália Mendes, (orgs.). Actas do XIX Encontro Nacional da Associação Portuguesa de Linguística. Lisboa: APL, pp. 555567.

Matos, Gabriela. 2006. Coordination de phrases vs. subordination adverbiale - propositions causales en portugais. In Brill, Isabelle \& Georges Rebuschi (orgs.) Faits de Langue - Revue de Linguistique nº 28 (Coordination et subordination: typologie et modélisation). Paris: Ophrys, pp. 169-180. ISSN 1244-5460.

Matos, Gabriela. 2009. Appositive sentences and the structure(s) of coordination. In Tork, Danièle \& Leo Wetzels (eds.) Romance Languages and Linguistic Theory 2006. Amsterdam \& Philadelphia: John Benjamins Publishing Company, 159-174.

Matos, Gabriela \& Madalena Colaço. 2010. A coordenação parentética como uma instância de adjunção. Textos seleccionados do XXV Encontro Nacional da Associação Portuguesa de Linguística, 2009. Porto: APL, pp. 607-622.

Matos, Gabriela \& Madalena Colaço. 2011. "Floating parenthetical coordinate clauses". In Berns, Janine, Haike Jacobs \& Tobias Sheer (eds.). Romance Languages and Linguistic Theory 2009, 203-221. Amsterdam \& Philadelphia: John Benjamins Publishing Company.

Matos, Gabriela \& Eduardo Raposo. 2013. Estruturas de coordenação. In Raposo, Eduardo B. P., M ${ }^{a}$ Fernanda B. Nascimento, Ma Antónia C. Mota, Luísa Segura \& Amália Mendes (orgs.) Gramática do Português, vol. II, cap. 35. Lisboa: Fundação Calouste Gulbenkia, 1761-1817.

Noordmann, Leo \& Femke de Blijzer. 2000. On the processing of causal relations.In Couper-Kuhlen, E. \& B. Kortmann, eds. Cause-Condition_Concession-Contast. Berlin: Mouton de Gruyter.

Peres, João. 1997. Sobre Conexões Proposicionais em Português. In Brito, Ana Maria, Fátima Oliveira, Isabel Pires de Lima e Rosa Martelo (orgs.) Sentido que a Vida Faz. Estudos para Óscar Lopes. Porto: Campo das Letras.

Peres, João \& Salvador Mascarenhas. 2006, Notes on sentential connections (predominantly). Journal of Portuguese Linguistics, 5(1): 775-567.

Quirk, R., S. Greenbaum, G. Leech \& J. Svartvik. 1985. A Comprehensive Grammar of the English Language, London: Longman.

Said Ali, Manuel. 1931. Gramática Histórica da língua Portuguesa. São Paulo: Edições Melhoramentos, 1964.

Santos Rio, Luis. 1982. Reflexiones sobre la expression de la causa en castellano. Studia Pholologica Salmanticensia, 6, 231-277.

Sanders, Ted, Wilbert Sporen \& Leo Norman. 1992. Toward a taxinomy of coherence relations. Discourse Processes. Norwood, vol 15, 1-35.

Schneider, Stefan. 2007. Reduced Parenthetical Clauses as Mitigators. Amsterdam/Philadelphia: John Benjamins.

de Vries, Mark. 2006. The Syntax of Appositive Relativization: On Specifying Coordination, False Free Relatives and Promotion. Linguistic Inquiry, 37(2): 229-270.

de Vries, Mark. 2007. Parentheses as B-merged adverbial phrases. In N. Déhé, \& Y. Kavalova. (eds.) Parentheticals. Amsterdam/Philadelphia: John Benjamins, 203-234.

de Vries, Mark. 2009. Specifying Coordination: An Investigation into the Syntax of Dislocation, Extraposition and Parenthesis. Dreyer (ed.): Language and Linguistics: Emerging Trends. NewYork: New Science Publishers. 